\title{
Investigating school quality and learning outcomes among adolescents in Malawi
}

Christine A. Kelly Population Council

Follow this and additional works at: https://knowledgecommons.popcouncil.org/departments_sbsr-pgy

Part of the Demography, Population, and Ecology Commons, Education Commons, Family, Life Course, and Society Commons, Gender and Sexuality Commons, International Public Health Commons, and the Medicine and Health Commons

How does access to this work benefit you? Let us know!

\section{Recommended Citation}

Kelly, Christine A. 2011. "Investigating school quality and learning outcomes among adolescents in Malawi," Promoting Healthy, Safe, and Productive Transitions to Adulthood Brief no. 34. New York: Population Council. 


\title{
Investigating school quality and learning outcomes among adolescents in Malawi
}

\author{
Prepared by Christine Kelly \\ With contributions from Paul Hewett, Barbara Mensch, and Erica Soler-Hampejsek
}

E

ducation, particularly at the primary level, has long been regarded as an essential input of social and economic development. In addition to its direct role in increasing the cognitive abilities of students, schooling is recognized as a facilitator of labor force participation, female empowerment, improved health outcomes, and greater civic engagement. In acknowledgment of the importance of schooling for future opportunities, as well as of persistent barriers to access in the developing world, universal primary education was listed as one of the eight United Nations Millennium Development Goals to be achieved by 2015. While it is clear that this goal will not be met, many countries have nonetheless made significant strides in improving access to primary schooling. The challenge they face is to increase the number of students without sacrificing the quality of education each receives.

As one of the early pioneers in sub-Saharan Africa of free primary education, Malawi's enrollment figures compare favorably with those of its neighbors in southern Africa. Before the elimination of fees in 1994, fewer than half of children attended primary school, but by 1999 net enrollment had reached 99 percent (United Nations Statistics Division 2010). ${ }^{1}$ However, this increase in access has not been accompanied by a corresponding investment in infrastructure and resources, such that "Malawi's decade-old, underfinanced and largely unplanned experiment in moving almost overnight to universal primary education is generally regarded as a failure" (Kenny 2010). Indeed, primary school completion rates stand at just 35 percent, while attainment of basic literacy and numeracy skills remains among the lowest in the region (World Bank 2010).

${ }^{1}$ This figure has declined somewhat in recent years.

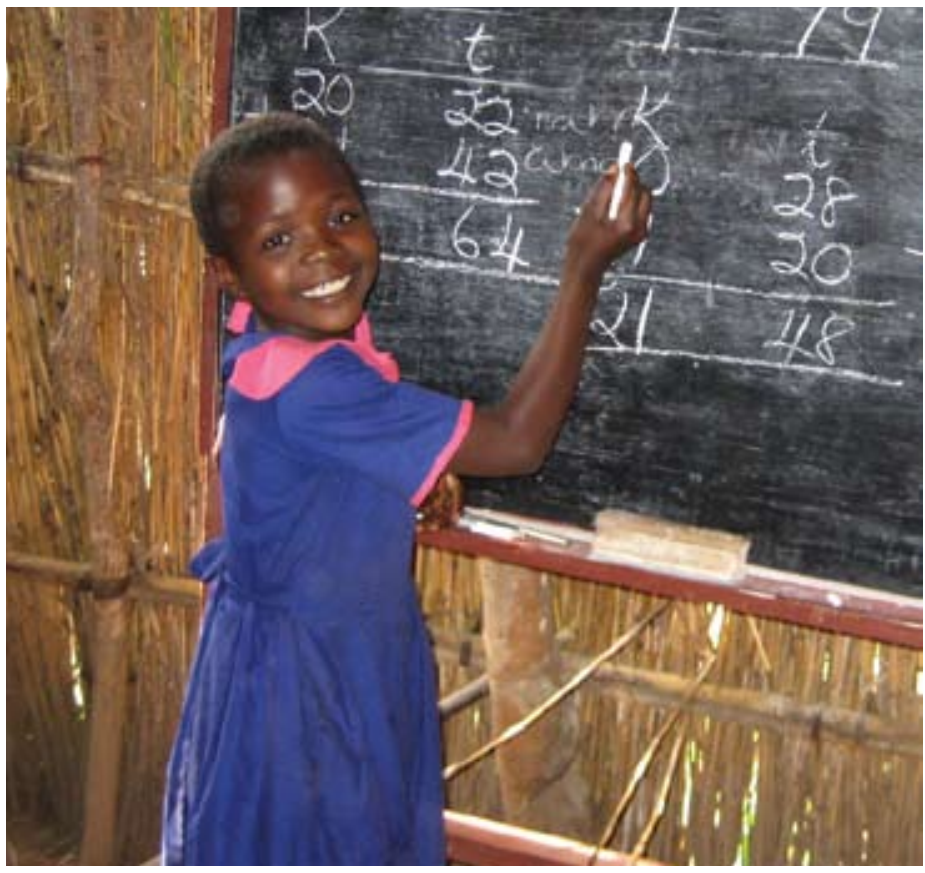

Against this backdrop, the Population Council's Plotting a Safe, Healthy, and Productive Path to Adulthood study seeks to formally investigate primary school quality and the schooling experiences of adolescents in two rural districts of Malawi. In particular, it explores the effect of school quality on educational outcomes, such as grade attainment, primary school completion, literacy, and numeracy. The study also seeks to assess the role of educational experience on other transitions to adulthood, including sexual initiation, marriage, and entrance into the labor force. Its longitudinal design, encompassing repeated assessments of the schooling environment and yearly follow-up of a sample of 
adolescents, enables the direct comparison of outcomes and experiences over time. In its first year in 2007, the study recruited 1,764 in-school adolescents and 886 out-of-school adolescents aged 14-16 and has maintained a follow-up rate of nearly 90 percent after four years. ${ }^{2}$

In addition to an extensive questionnaire covering such topics as schooling history, family background, formal and informal labor, and sexual behavior, adolescents were asked to complete short literacy and numeracy tests, pitched at the level of the standard (grade) 3 curriculum. School quality data were collected via questionnaires administered to teachers and head teachers from 59 study schools, and supplemented by facilities inventories carried out by study staff.

In January 2011, Population Council researchers, along with collaborators at the Centre for Educational Research and Training (CERT), University of Malawi, hosted a dissemination workshop to discuss preliminary findings from the first three rounds of data collection, as well as future avenues for research. In attendance were a variety of stakeholders, including Ministry of Education officials, teachers, researchers, donors, and representatives from leading NGOs, resulting in very fruitful dialogue.

\section{A snapshot of school quality and outcomes}

Population Council findings corroborate the gloomy picture of Malawian school quality reported elsewhere (World Bank 2010, Kenny 2010, Chimombo et al. 2005, Clemens 2004). The 59 study schools were under-staffed, under-resourced, and over-crowded, with the worst conditions in the four earliest standards. High enrollments resulted in student-teacher ratios in excess of 100:1 (Figure 1), while half of schools lacked a classroom for one or more standards. Unfortunately, despite more manageable class sizes and facilities for older students, other problems remain. Curriculum materials, including textbooks and teaching manuals, are in short supply. As of 2008 , as many as onequarter of interviewed teachers had not completed secondary school, leaving them short of the recommended academic qualification. Women were severely underrepresented in the teaching force, with 68 percent of study schools reporting one quarter or fewer of their teachers as female in 2007; 21 percent of schools had no female teachers at all. This leaves a vast proportion of girls without female role models.

In view of these conditions, it is perhaps not surprising that schooling outcomes in Malawi are poor. Pupils tested on standard 3-level material in standard 4 demonstrated competencies substantially below what would be expected for their grade: in 2007, fewer than 10 percent of pupils could answer at least 11 of the 12 math questions; fewer than 20 percent could read two simple sentences in English. English literacy did improve as the standard level increased-particularly after standard 5 when the language of instruction switches to English from Chichewa-such that by standard 8 , more than 90 percent of pupils could read the two sentences (Figure 2). Math outcomes were slightly

${ }^{2}$ According to the 2004 Malawi Demographic and Health Survey, 77 percent of 14-16year-olds enrolled in school are attending standards $1-4$, so the in-school sample consists of adolescents in these grades.
Figure 1 Mean number of students per teacher, by standard

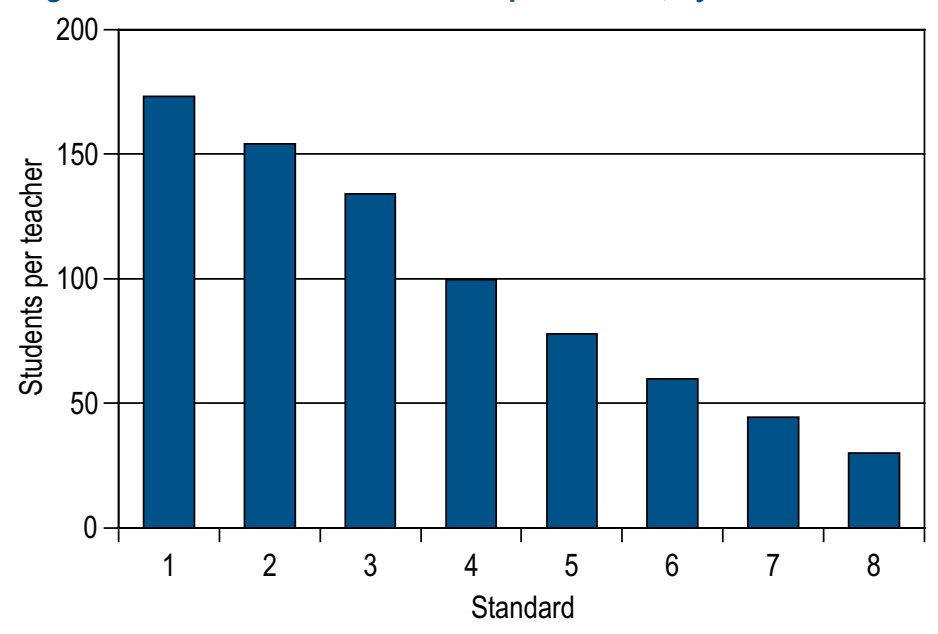

Student-teacher ratios are exceptionally high in the four earliest standards.

Figure 2 Percent of students who correctly completed English and math tests (2007)

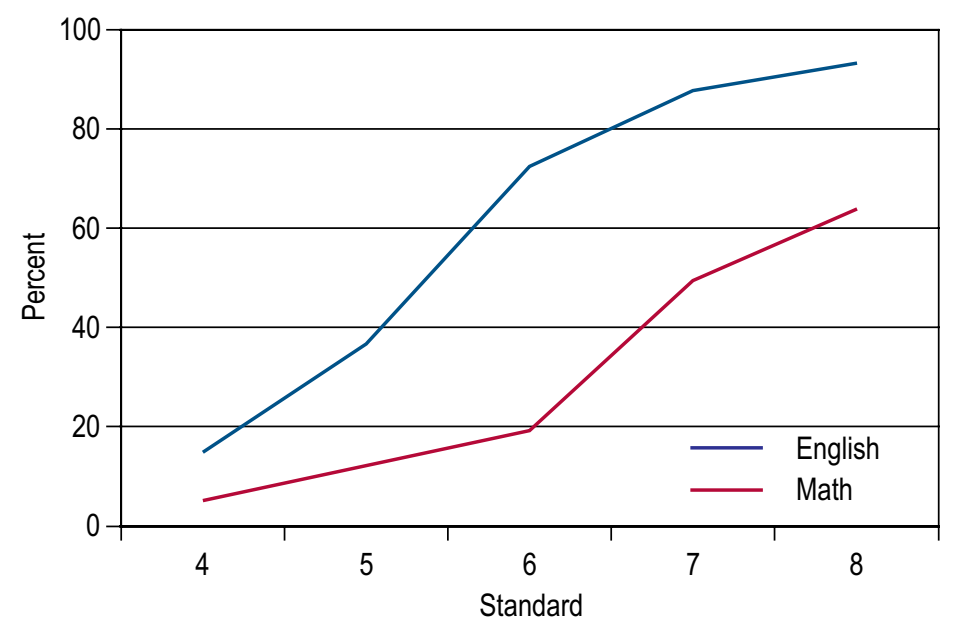

Performance in English is higher than in math for students in every standard. Literacy skills appear to facilitate learning in other subjects.

less encouraging. While there was again improvement in test scores with each standard, only 60 percent of standard 8 pupils achieved a score of at least 11 on the same 12-question math test. Interestingly, the most significant improvement in numeracy skills occurred between standards 6 and 7 , suggesting that literacy may facilitate learning in other subjects.

The longitudinal data provide an additional, and alarming, insight about the retention of skills upon school-leaving. They offer clear evidence that, as early as one year after leaving primary school, adolescents score lower on the same literacy and numeracy tests than they 


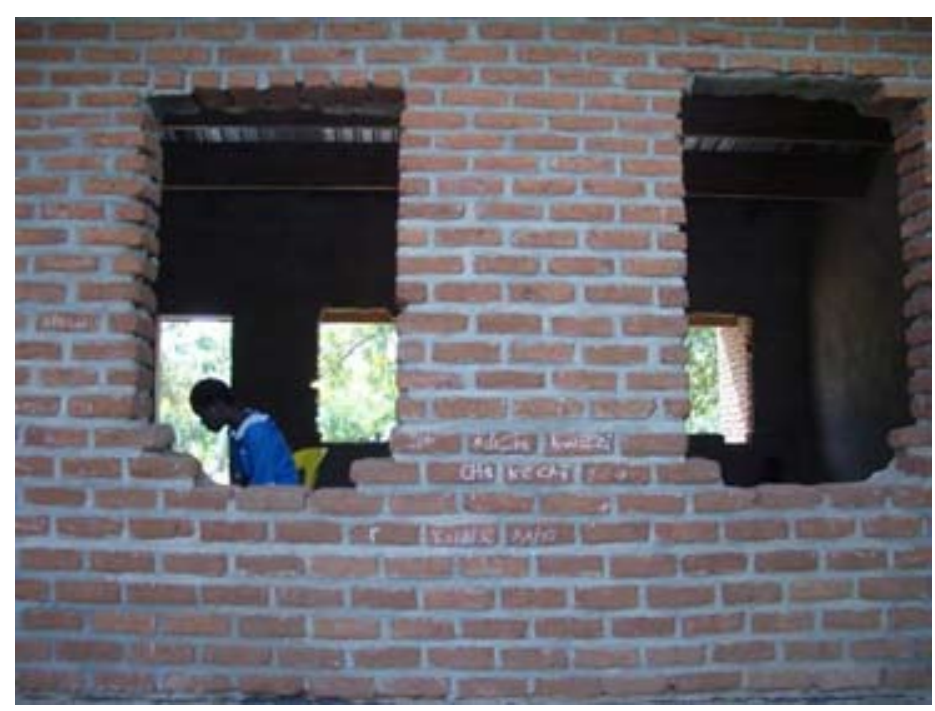

did when they were still enrolled, especially if they did not complete the primary cycle. This "de-learning" applies for both boys and girls, and for English and math.

\section{Determinants of learning}

Although the adolescent study focuses primarily on experiences in standards $4-8$, it is unquestionable that conditions in earlier standards influence later learning. Drop out and repetition rates are high during this period and evidence from the study's out-of-school sample shows that students who progress no further than standard 3 exhibit almost no learning in any subject. Pupils who succeed in reaching standard 4 demonstrate very limited literacy and numeracy skills, although competencies do improve thereafter. Population Council research sought to identify the factors that help facilitate learning in later standards.

Controlling for individual-, household-, and school-level characteristics, ability to read in English-a prerequisite for progression into secondary school-was, unsurprisingly, related to standard-level: the more advanced in schooling, the greater the likelihood of being able to read. More revealingly, adolescents with a female teacher in their current standard performed better than those adolescents-girls or boys-who did not. For boys, having a school uniform increased performance, which may reflect a familial commitment to education, or a greater sense of self-esteem. For girls, those who struggled to progress through standards 1-3-that is, they repeated at least one grade-had more trouble with reading than those girls who repeated fewer times. This finding provides one example of how schooling experiences in early standards affect performance in later years.

As with English, math competency increased with standard-level for the youngest members of the sample. For both boys and girls, numeracy skills were strongly associated with the ability to read in English, providing support for the hypothesis that literacy facilitates other learning. Uniforms were again significant predictors of learning for boys and of early repetitions for girls. However, having a female teacher did not seem to improve math performance.

\section{Implications for policy and research}

On its current trajectory, the future of Malawian primary education looks bleak. Chronic shortages of material resources and human capital will be compounded by severe demographic pressures, such that a projected 4.8 million additional children will need primary school places by 2018 (World Bank 2010). Participants at the Population Council/ CERT workshop agreed that large-scale supply-side initiatives should be at the top of the education policy agenda. In setting a target studentteacher ratio at 60:1 the Malawian government has already recognized the need to recruit more teachers and to lower class sizes. That the figure remains high indicates the magnitude of the challenge ahead. Building additional classrooms for early standards would further ease overcrowding, while investment in female teachers would improve learning and provide pupils with female role models.

However, this variety of structural intervention is both time- and resource-intensive, both of which are limited for the current generation of students. In the short to medium term, a number of other innovative initiatives could be tried. Compensating teachers for double shifting, whereby one set of students is taught in the morning and a second wave in the afternoon, would reduce class sizes within the constraints of existing facilities. Given the immediate need for teachers and the challenges of training sufficient numbers in a short period of time, consideration should also be given to an international "teacher corps" as a stop-gap measure.

As has already been shown among Kenyan pupils (Evans et al. 2008), a uniform distribution program might help improve school performance, particularly among boys. In addition, community-based approaches could be used to supplement school-level interventions. Those that create a culture of reading, such as building libraries or promoting in-country publication of books, could bolster literacy skills. Since reading seems to enhance learning in other subjects, these programs could also have additional benefits.

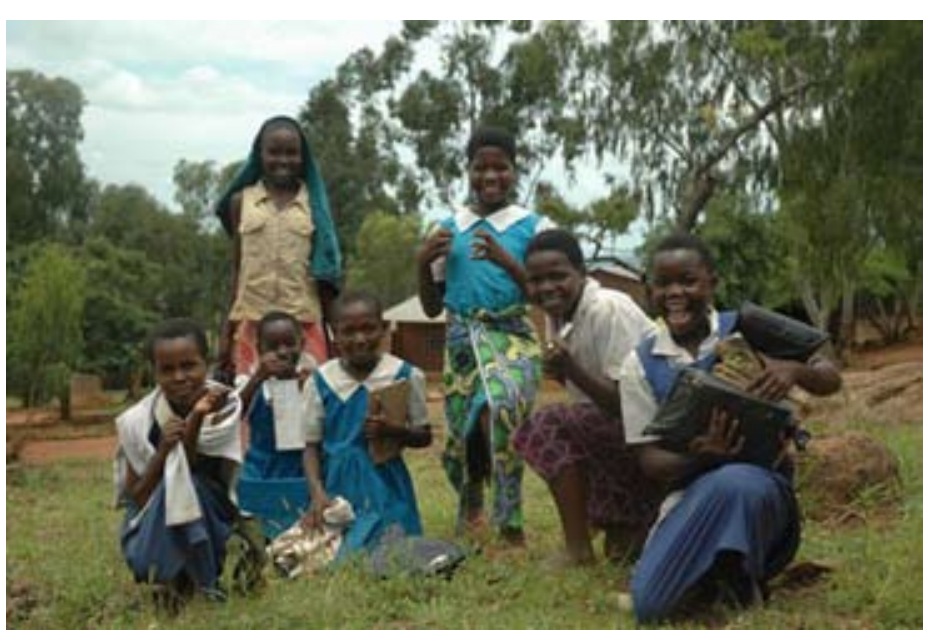


Although there was strong agreement that the deterioration of school quality in Malawi must be arrested, the dissemination meeting made clear that there is at present little consensus among local and international stakeholders regarding the most appropriate means to improve outcomes. This is largely because very few programs-in Malawi or elsewhere-have been rigorously evaluated. More attention is needed to assess the impact of the multitude of initiatives being rolled out in developing countries in order to identify the most effective interventions.

\section{References}

Chimombo, Joseph, Demis Kunje, Thokozire Chimuzu, and Clive Mchikoma. 2005. "The SAQMEQ II Project in Malawi: A Study of the Conditions of Schooling and the Quality of Education." Harare: SAQMEQ.

Clemens, Michael. 2004. "The Long Walk to School: International Education in Historical Perspective."Center for Global Development Working Paper 37. Washington, DC: Center for Global Development.

Evans, David , Michael Kremer, and Mũthoni Ngatia. 2008. "The Impact of Distributing School Uniforms on Children's Education in Kenya." Unpublished manuscript.
Kenny, Charles. 2010. "Learning About Schools in Development." Center for Global Development Working Paper 236. Washington, DC: Center for Global Development.

National Statistical Office (NSO) [Malawi], and ORC Macro. 2005. "Malawi Demographic and Health Survey 2004." Calverton, Maryland: NSO and ORC Macro.

United Nations Statistics Division. 2010. "Total net enrolment ratio in primary education, both sexes." Millennium Development Goals Indicators. Retrieved 10 February 2011 (http://millenniumindicators.un.org/unsd/mdg/ SeriesDetail.aspx?srid=589\&crid=454).

World Bank. 2010. "The Education System in Malawi." World Bank Working Paper 182. Washington, DC: World Bank.

\section{Donor Acknowledgment:}

The project described was supported by the Spencer Foundation, the Eunice Kennedy Shriver National Institute of Child Health and Human Development, NICHD (Grant No. R01HD47764), the William and Flora Hewlett Foundation, the John D. and Catherine T. MacArthur Foundation, and the UK Department for International Development (DFID). Its contents are solely the responsibility of the authors and do not necessarily represent the official views of the NICHD.

\section{Population Council}

The Population Council changes the way the world thinks about critical health and development issues. We seek to understand the causes and consequences of gender inequality and the disparities in opportunity that arise during adolescence. We provide the evidence for better on-theground programs and policies that ensure successful and productive transitions to adulthood in developing countries. www.popcouncil.org

(C) 2011 The Population Council, Inc. 